\title{
A canonical structure for the ligand-binding domain of nuclear receptors
}

\author{
Jean-Marie Wurtz, William Bourguet, Jean-Paul Renaud, Valérie Vivat, Pierre Chambon, Dino Moras \\ and Hinrich Gronemeyer \\ Nature Structural Biology 3, 87-94 (1995).
}

Fig. 2 Sequence alignment of nuclear receptor LBDs. This figure was inadvertently cropped on the left. The version below is as it should have appeared in last month's issue.

\begin{tabular}{|c|c|}
\hline hTR:I 1 & 209 \\
\hline hPPAR $\alpha$ & 199 \\
\hline hROR1 & 269 \\
\hline hVDR & 124 \\
\hline d875A & 339 \\
\hline TNGPI - B & 322 \\
\hline $\mathrm{hRAR}_{f}$ & 182 \\
\hline hRXRu & 224 \\
\hline I HAY - 4 & 135 \\
\hline dUSP & 232 \\
\hline hCOUP-TrI & 181 \\
\hline hER & 308 \\
\hline hPR & 680 \\
\hline $\mathrm{h} A \mathrm{R}$ & 666 \\
\hline haR & 525 \\
\hline hMR & 731 \\
\hline
\end{tabular}

hTR:

hPPA

hROR

hVDR

r NGYI - B

hRAR:

hNXR:

THNP -

dusp

COUP-TYI 213

$\mathrm{hBR}$

hPR

hAR

hMR

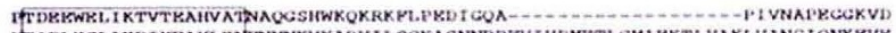

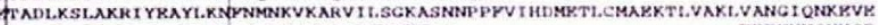
FUARLBHLAQNI SKSHLKTCOYLREELOOITWOTYL.Q- -

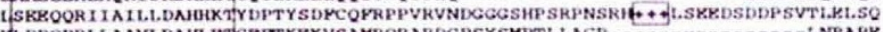
CL.DDQPRLL.AAVLRAIL.KTCEFTKKXVS SMRQRARDCPSYSMTTLLACP -

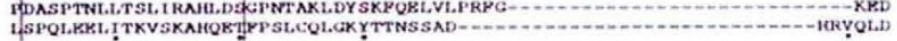

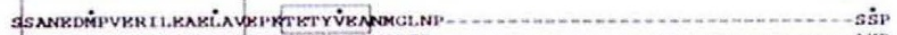

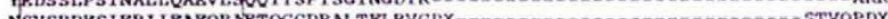

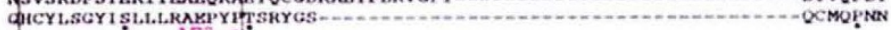

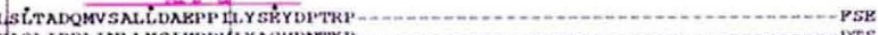

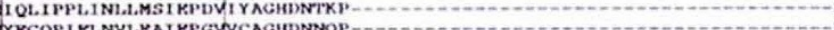

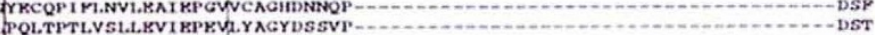
PRALTPSPVMVI.KNIRPKIVYAGYDSSKP. $\begin{array}{ll}\mathrm{H} 1 & \text { (H2) }\end{array}$

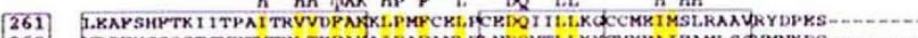

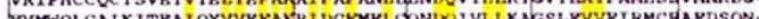
TSMI.

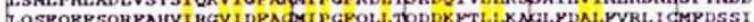
AgDVOPYPDI

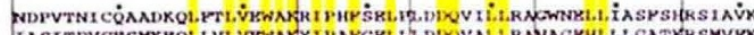
XGXVSALCOVVNKOL

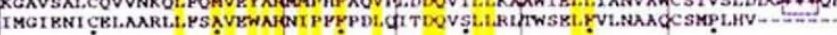

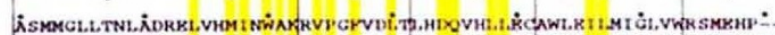

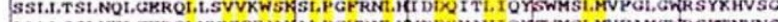
Aal.LssL

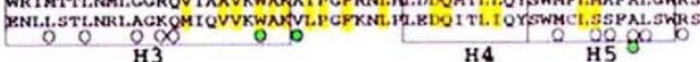

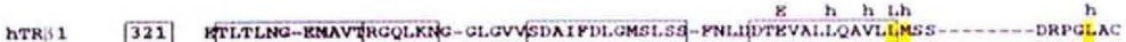

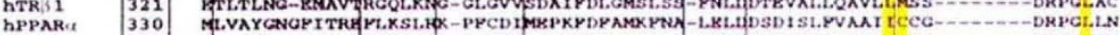

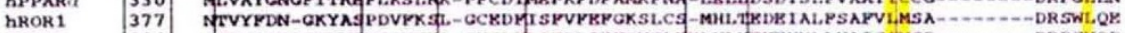

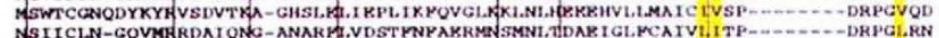

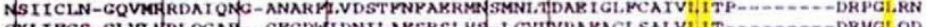

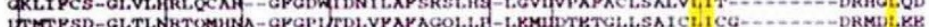

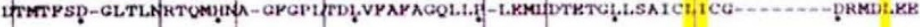

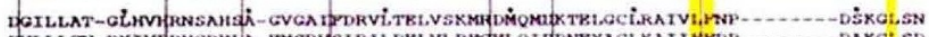

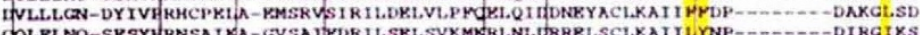

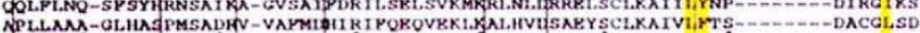

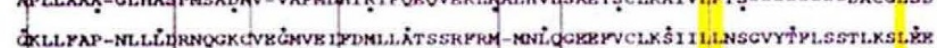
C.

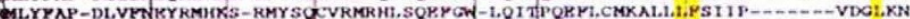

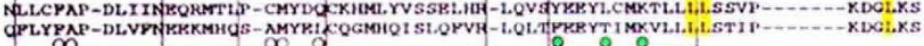

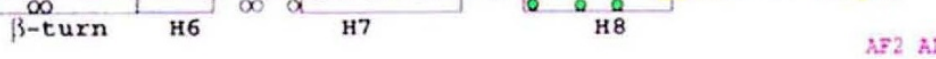

cose

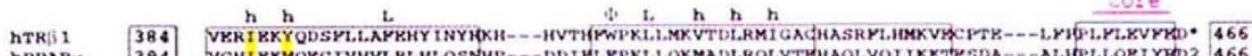
TPPAR

hVDK

AR75A TNGPI $-\mathrm{B}$ TRGP I-
hRAR?

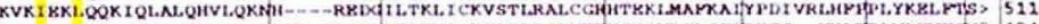

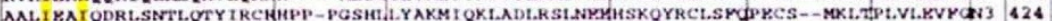

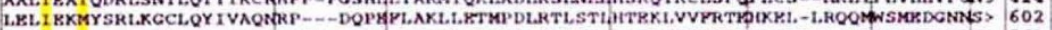

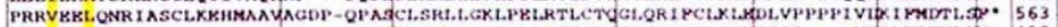

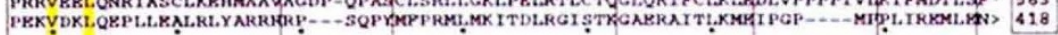

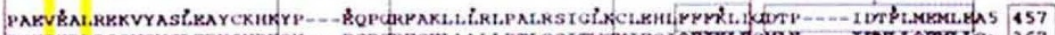

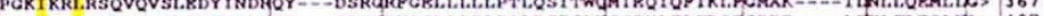

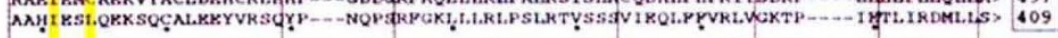

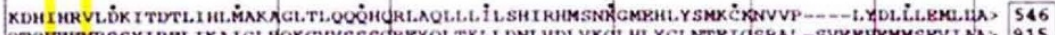
GTQFERARS3Y

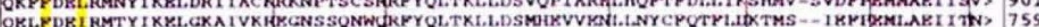

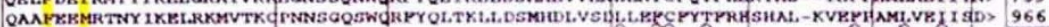

